\title{
Psychological characteristics of developing excellence in mixed martial arts athletes
}

\author{
Roberto RUIZ BARQUÍN*1, Adrián PLURA MALDONADO ${ }^{*}$ \& Carlos GUTIÉRREZ-GARCÍA² \\ ${ }^{1}$ Universidad Autónoma de Madrid (Spain) \\ 2 Universidad de León (Spain)
}

8th IMACSSS International Conference Abstracts, Viseu (Portugal), October 10-12, 2019 Type: Oral communication

\begin{abstract}
The aim of this study was to describe the perception of sports talent and excellence development in a sample of MMA fighters, and compare the obtained results with those of previous studies. A total of 42 adult (male and female) MMA athletes of several levels (amateur, semi-professional and professional) participated in the study. A socio-demographic questionnaire and the Psychological Characteristics of Developing Excellence Questionnaire - PCDEQ were used for collecting data. Statistical analyses included descriptive statistics and student's $t$-test for means comparison. In general, MMA athletes obtained higher scores than those reported by samples of other sports in previous studies, and more specifically in factors I - Support for long-term success, II - Imagery use during practice and competition, and IV - Ability to organise and engage in quality practice. This can be explained due to the higher average age of our sample and the professional or semiprofessional level already achieved by many of the MMA fighters. The study also revealed that MMA fighters may need specific psychological training related to factor III - Coping with performance and developmental pressures.
\end{abstract}

Keywords: Martial arts; combat sports; mixed martial arts; MMA; talent identification; talent development; sports excellence.

\section{Introduction}

One of the most developed lines of research in Sport Psychology is the study of sports talent, not only at a descriptive level but also at a predictive level, including the short, medium and long term. Despite the existence of multiple self-assessment questionnaires for the direct or indirect evaluation of psychological performance (see e.g. Gimeno, Buceta, \& Pérez-LLantada, 2001; Hernández-Mendo, 2006), many of them focus on non-global selective measurements (strictly of psychological factors) and exclusively assess the perception of sports performance in the present but not in the future (short, medium or long term).

\section{Objectives}

The aim of this study was to describe the perception of sports talent and excellence development in a sample of MMA fighters, and compare the obtained results with those of previous studies.

\section{Methodology}

This was a cross-sectional, descriptive study of populations through survey research (Montero \& Leon, 2007). The protocol for this study was approved by the Ethics Committee of the Universidad Autónoma de Madrid, Spain.

A total of 42 adult $\left(M \pm S D_{\text {age }}=26.21 \pm 3.81\right.$ years $)$ male $\left(n=34 ; M \pm S D_{\text {age }}=26.21 \pm 3.94\right.$ years $)$ and female $\left(n=8 ; M \pm S D_{\text {age }}=26.26 \pm 3.45\right.$ years $)$ MMA athletes participated in this study. Their sport

\footnotetext{
*Email: roberto.ruiz@uam.es
} 
level was amateur ( $n=27 ; 64.3 \%)$, semi-professional $(n=7 ; 16.6 \%)$ and professional $(n=8 ; 19 \%)$. Up to $59.5 \%(n=25)$ had studied at the university level, $23.8 \%(n=10)$ secondary education, $4.8 \%$ $(n=2)$ basic education and $11.9 \%(n=5)$ had other studies. Their training regime included from three to seven training days per week $(M \pm S D=5.05 \pm 1.03)$ for a total training ranging from 2 and 40 hours per week $(M \pm S D=10.50 \pm 6.65)$.

A socio-demographic questionnaire (adapted from Ruiz-Barquín, de la Vega, \& Redón; in Redón, 2010) and the Psychological Characteristics of Developing Excellence Questionnaire PCDEQ (McNamara \& Collins, 2011, 2013, Spanish version Ruiz-Barquín, García-Carrión, \& de la Vega, 2014) were used for this study. The first is composed of 14 items aimed at characterizing the sample. The PCDEQ is composed of 59 items and 6 factors, namely Support for long-term success (17 items), Imagery use during practice and competition (12 items), Coping with performance and developmental pressures (11 items), Ability to organise and engage in quality practice (7 items), Evaluating performances and working on weaknesses (5 items), and Support from others to compete to my potential ( 7 items). Each item is answered on a Likert-type scale ranging from 1 (very unlike me) to 6 (very like me). Once the informed consent was obtained from all participants, each of them completed the questionnaires in a single session.

All statistical analyses were performed using SPSS Statistics (v. 22.0) and included descriptive statistics (frequencies, percentages, means and standard deviation) and student's $t$-test for means comparison.

\section{Results}

Table 1 displays the results obtained for the six PCDEQ factors in our study, as well as in the studies used for comparison. MMA fighters obtained high scores in all factors, ranging from 4.02 to 5.04 points.

Table 1. Descriptive results.

\begin{tabular}{lcccccc}
\hline & $\mathbf{( 1 )}$ & $\mathbf{( 2 )}$ & $\mathbf{( 3 )}$ & $\mathbf{( 4 )}$ & $\mathbf{( 5 )}$ & $\mathbf{( 6 )}$ \\
\cline { 2 - 7 } & $\boldsymbol{M}(\boldsymbol{S D})$ & $\boldsymbol{M}(\boldsymbol{S D})$ & $\boldsymbol{M}(\boldsymbol{S D})$ & $\boldsymbol{M}(\boldsymbol{S D})$ & $\boldsymbol{M}(\boldsymbol{S D})$ & $\boldsymbol{M}(\boldsymbol{S D})$ \\
\hline Factor I & $4.25(0.65)$ & $3.99(0.78)$ & $4.36(.60)$ & $3.90(.73)$ & $4.08(.86)$ & $4.87(.70)$ \\
Factor II & $3.89(0.99)$ & $3.81(0.91)$ & $4.18(.69)$ & $3.80(.70)$ & $4.29(.78)$ & $4.53(.74)$ \\
Factor III & $4.27(0.77)$ & $3.87(0.86)$ & $3.61(.66)$ & $3.45(.82)$ & $4.38(.90)$ & $4.02(.96)$ \\
Factor IV & $4.90(0.61)$ & $4.77(0.58)$ & $4.76(.66)$ & $4.29(.68)$ & $4.67(.75)$ & $4.83(.71)$ \\
Factor V & $4.99(0.72)$ & $4.56(0.85)$ & $4.90(.74)$ & $4.71(.75)$ & $4.83(.75)$ & $5.04(.90)$ \\
Factor VI & $4.62(.063)$ & $4.45(0.64)$ & $4.35(.64)$ & $4.13(.61)$ & $4.74(.76)$ & $5.04(.92)$ \\
\hline
\end{tabular}

(1) Good developers (team sport participants, $n=134$ ); (2) Poor developers (team sport participants, $n=49$ );

(3) Good developers (individual sport participants, $n=52$ ); (4) Poor developers (individual sport participants, $n=34$ ); all these samples from MacNamara and Collins (2013); (5) football participants ( $n=$ 316), sample from Ruiz-Barquín, García-Carrión and De la Vega (2014); (6) Present study. Factor I: Support for long-term success; Factor II: Imagery use during practice and competition; Factor III: Coping with performance and developmental pressures; Factor IV: Ability to organise and engage in quality practice; Factor V: Evaluating performances and working on weaknesses, and Factor VI: Support from others to compete to my potential.

MMA fighters obtained higher values in Factor I compared to other sport samples in previous studies $(p<.001)$, also in Factor II (all of them with $p<.001$ but for study $3, p<.01$, and 5, $p<.05$ ) and Factor VI (all of them with $p<.001$ but for studies 1 and $5, p<.01$ ). Regarding Factor III, higher scores were achieved in the MMA sample compared to samples of studies $3(p<.01)$ and $4(p<.001)$, but lower scores when compared with study $5(p<.05)$. As for Factor IV, MMA fighters achieved higher scores than participants in study $4(p<.001)$. Finally, despite the group of MMA fighters obtaining the highest score in Factor $\mathrm{V}$, only significant differences were found compared to studies $2(p<.001)$ and $4(p<.05)$.

\section{Discussion and Conclusion}

This study has described the psychological characteristics associated with the development of excellence in a sample of MMA fighters of different competitive levels. In general, the high scores 
obtained by the group of MMA fighters may be due to the high average age of our sample (26.21 years) compared to 15.94 years (team sports) and 16.72 years (individual sports) of MacNamara and Collins' (2013) study, and 17.77 years of the study by Ruiz-Barquín, García-Carrión and De la Vega (2014). Obviously, the needs and requirements of talent development may depend largely on the athlete's stage of development (MacNamara, Button, \& Collins, 2010a, b). Similarly, many of the MMA fighters in our sample (36.6\%) were professional or semi-professional. The level already achieved by these athletes, as well as the existing economic factor, may be a relevant component in their perception of their development of sports talent and excellence. On the other hand, the lower score obtained in Factor III (Coping with performance and developmental pressures) suggests the need to implement specific psychological training with these athletes in order to improve their stress coping strategies, which is in line with the purposes of the PCDEQ (MacNamara \& Collins, 2011, 2013).

In conclusion, the PCDEQ has allowed characterizing as high the perception of the development of sports talent and the excellence of a sample of MMA athletes, as well as detecting potential elements to implement training at a psychological level. Future studies should increase the sample size and include younger athletes, in order to complete the panorama of the perception of the development of sports talent and excellence in MMA.

\section{References}

Gimeno, F., Buceta, J.M., \& Pérez-Llantada, M.C. (2001). El cuestionario Características Psicológicas relacionadas con el Rendimiento Deportivo CPRD: Características psicométricas. Análise Psicológica, 1(19), 93-113.

Hernández-Mendo, A. (2006). Un cuestionario para la evaluación psicológica de la ejecución deportiva: estudio complementario entre TCT y TRI. Revista de Psicología del Deporte, 15(1), 71-93.

Montero, I., \& León, O. G. (2007). A guide for naming research studies in Psychology. International Journal of clinical and Health psychology, 7(3), 847-862.

MacNamara, Á., Button, A., \& Collins, D. (2010a). The role of psychological characteristics in facilitating the pathway to elite performance. Part 1: Identifying mental skills and behaviours. The Sport Psychologist, 24(1), 52-73. doi: 10.1123/tsp.24.1.52

MacNamara, Á., Button, A., \& Collins, D. (2010b). The role of psychological characteristics in facilitating the pathway to elite performance. Part 2: Examining environmental and stage related differences in skills and behaviours. The Sport Psychologist, 24(1), 74-96. doi: $10.1123 /$ tsp.24.1.74

MacNamara, A \& Collins, D. (2011). Development and initial validation of the Psychological Characteristics of Developing Excellence Questionnaire. European Journal of Sports Sciences, 29(12), 1273-1286. doi:10.1080/026404 14.2011.589468

MacNamara, A \& Collins, D. (2013). Do mental skills make champion? Examining the discriminant function of the psychological characteristics of the developing excellence questionnaire. Journal of Sports Sciences, 31(7), 736-744. doi: 10.1080/02640414.2012.747692

Redón, G. (2010). Evaluación del liderazgo y satisfacción en el deporte del Fútbol a partir del Modelo de Liderazgo de Chelladurai (Unpublished Master's Thesis). Universidad Autónoma de Madrid, Madrid (Spain).

Ruiz-Barquín, R., de la Vega Marcos, R., \& García Carrión, I. (2014). Adaptación al castellano del cuestionario "Características Psicológicas del Desarrollo de la Excelencia (PCDEQ). In Libro de Actas del XIV Congreso Nacional y I Congreso Internacional de Psicología de la Actividad Física y el Deporte. Cáceres, España: Universidad de Extremadura. 